\title{
Disruption of latent inhibition by interpolation of task-irrelevant stimulation between preexposure and conditioning
}

\author{
MARTHA ESCOBAR and FRANCISCO ARCEDIANO \\ Auburn University, Auburn, Alabama \\ and \\ RALPH R. MILLER \\ State University of New York, Binghamton, New York
}

\begin{abstract}
Latent inhibition refers to attenuated responding to a conditioned stimulus (CS) that was repeatedly presented without reinforcement prior to the CS-unconditioned stimulus (US) pairings. Using water-deprived rats as subjects, we observed that interpolating task-irrelevant stimulation between the preexposure and conditioning phases of a latent inhibition procedure attenuated latent inhibition (Experiments 1A, 1B, and 2). Apparently, interpolated stimulation segments the preexposure and conditioning treatments into two separate experiences, much in the same way that a change of context would. Consistent with this view, the interpolated stimulation did not disrupt latent inhibition if it was also presented during both preexposure and conditioning (Experiment 3). We view these results as analogous to those of Escobar, Arcediano, and Miller (2003), who suggested that the difficulty in observing latent inhibition in human adults is related to the segmentation between preexposure and conditioning caused by the usual interpolation of instructions in preparations with humans.
\end{abstract}

Latent inhibition (also known as the "CS-preexposure effect") is defined as retarded acquisition or expression of an association between a conditioned stimulus (CS) and an unconditioned stimulus (US) that results from repeated presentation of the CS without the US, prior to the CS-US pairings (i.e., CS-noUS trials followed by CS-US trials; Lubow, 1973, 1989; Lubow \& Moore, 1959). Several theoretical explanations have been advanced to account for the development of latent inhibition. According to some views, preexposure treatment decreases attention to (or associability of) the CS, thus preventing the formation of a CS-US association during the subsequent conditioning phase (e.g., Lubow, Weiner, \& Schnur, 1981; Mackintosh, 1975; Pearce \& Hall, 1980). Other theories, however, posit that latent inhibition results from associations formed between the CS and the context during CS-preexposure treatment, which then attenuate either the formation (e.g., Wagner, 1981) or expression (e.g., Miller \& Matzel, 1988)

Support for this research was provided by NIMH Grant 33881. M.E. was supported by a Dissertation Year Fellowship from the State University of New York at Binghamton. F.A. was supported by Basque Government Fellowship BFI97.013. The authors thank Jeffrey Amundson, Steven Stout, Koji Urushihara, and Daniel Wheeler for their comments on a preliminary version of the manuscript. Special thanks are also due James Esposito and Monica Zgola for their assistance with collecting data. Inquiries concerning this research should be addressed to R. R. Miller, Department of Psychology, SUNY-Binghamton, Binghamton, NY 139026000, USA (e-mail: rmiller@binghamton.edu). of a CS-US association. The observation that, if the preexposure and conditioning treatments occur in different contexts, latent inhibition is greatly attenuated (e.g., Channell \& Hall, 1983; Lovibond, Preston, \& Mackintosh, 1984) strongly supports the CS-context association view. "Context" is traditionally defined as the physical environment in which a particular treatment takes place. However, context is also determined by temporal (e.g., Bouton, 1993) and local cues (e.g., Barnet, Grahame, \& Miller, 1993) of the training situation. "Local contexts" can be assumed to develop around cues that are consistently trained together. The present experiments explore how local cues may affect the development of latent inhibition.

Some background on the relevance of local contexts for the development of latent inhibition can be extracted from studies of latent inhibition that used human participants. Latent inhibition has been observed in a variety of species (for a review, see Lubow, 1973); however, it has been difficult to obtain in human adults. The prevailing literature suggests that observing latent inhibition in human adults requires that preexposure CS presentations be "masked," that is, the CS must be presented while the participant is engaged in a distracting, irrelevant task (e.g., BraunsteinBercovitz \& Lubow, 1998a, 1998b; de la Casa \& Lubow, 2001; Graham \& McLaren, 1998; Hulstijn, 1978). According to some views (e.g., those of Lubow \& Gewirtz, 1995), masking is necessary because it engages the controlled components of attention, thereby leaving processing of the CS to the automatic components of attention (for an overview of the difference between automatic and 
controlled processing, see Schneider \& Shiffrin, 1977; Shiffrin \& Schneider, 1977). Some theorists (see, e.g., Lubow, 1989; Lubow \& Gewirtz, 1995) have suggested that latent inhibition occurs at the automatic level and, in human adults, the controlled components of attention may override the automatic components of attention. Presumably, controlled processing of the preexposed CS hinders the development of latent inhibition. Indeed, these theorists suggest that if controlled processes are not well developed (which is, according to this view, the case in nonhuman animals and young children), latent inhibition should develop without need for a masking task.

Recently, Escobar, Arcediano, and Miller (2003) suggested that the difficulty in obtaining latent inhibition in human adults was related to the procedures used in those studies. They noted that the procedure used in experiments with human participants (e.g., Ginton, Urca, \& Lubow, 1975) differs from that used with animals in that the human procedure usually involves the participants' receiving instructions about the task both before preexposure and before conditioning. Moreover, in many circumstances, the task is changed between preexposure and conditioning. Escobar et al. hypothesized that human situations that resemble the animal situation by having no interruption in the transition between preexposure and conditioning would yield latent inhibition without masking. To test this hypothesis, they developed a contingency judgment task in which unmasked cue preexposure and conditioning occurred without interruption. In this preparation, participants were asked to observe and attend to the events that would be presented on a computer monitor (i.e., the task was explicitly unmasked in that participant's attention was directed to the target stimuli). The events were a series of colored letters. During the preexposure phase, participants were repeatedly presented with two of the letters (CSs X and B); during conditioning, CSs X and A were followed by the brief presentation of a white cross (i.e., the outcome). At test, participants were asked to rate the likelihood that each of the three CSs (X, A, and B) would predict the occurrence of the white cross. Consistent with the observation of latent inhibition, the ratings were higher for CS A than for CS X. Moreover, if a redundant set of instructions was interpolated between preexposure and conditioning, latent inhibition was attenuated (i.e., ratings of CSs A and X did not differ from each other) to a level similar to the attenuation observed after a change of context between preexposure and conditioning. Escobar et al. concluded that presenting instructions between preexposure and conditioning disrupted the continuity of the task, which might have encouraged participants to regard the events occurring prior to the redundant instructions as irrelevant to the conditioning task; that is, the instructions effectively constituted a change of context.

The preparations used for nonhuman research avoid the problem of having to instruct the subject on the details of the task. Instructions are usually regarded as background information, but noninformative irrelevant text, such as that used by Escobar et al. (2003), can be viewed as a form of salient, task-irrelevant stimulation. Thus, one may wonder if, using nonhuman subjects, interpolation of task-irrelevant stimulation (akin to redundant instructions) between preexposure and conditioning would result in attenuated latent inhibition in a situation in which latent inhibition would have otherwise been observed. Previous research has suggested that this expectation is well founded. For example, Lantz (1973, Experiment 3) observed that presentation of a "dishabituating" stimulus immediately before conditioning attenuated the effects of CS preexposure (i.e., robust behavioral control by the preexposed CS was observed) on conditioned lick suppression with rat subjects. However, a potential problem with Lantz's study is that it did not dissociate the habituation and the latent inhibition effects that resulted from the CS-preexposure treatment. That is, the CS-preexposure presentations occurred with short intertrial intervals just prior to conditioning; thus, any effects of (short-term) habituation would not have waned by the time conditioning took place (see Hall, 1991, for a discussion of the difference between habituation and latent inhibition). Rudy, Rosenberg, and Sandell (1977) observed that exposing rats to "exteroceptive" stimulation (i.e., placement in a black box) between preexposure to a flavor and pairings of that flavor with lithium chloride-induced illness disrupted the attenuating effects of flavor preexposure on conditioned taste aversion. Latent inhibition was not disrupted if the rats were placed in the black box (1) prior to the preexposure phase, (2) interspersed with the CS presentations in the preexposure phase, (3) interspersed with the CS presentations in the conditioning phase, or (4) between the CSs and the US presentation in the conditioning phase. Rudy et al. concluded that novel interpolated stimulation would attenuate the effects of CS preexposure only if it was given immediately before the conditioning CS presentation. A potential problem in generalizing the Rudy et al. results is that the study involved conditioning with an internal state as the US (i.e., internal malaise), whereas the interpolated stimulation involved an external stimulus (i.e., a change in the environment). Moreover, because the interpolated stimulation consisted of placement in a compartment different from the treatment context, it is possible that attenuation of latent inhibition occurs only when subjects are exposed to a novel context between preexposure and conditioning (see our General Discussion for further elaboration of this point).

In the present studies, we attempted to extend the results of Escobar et al. (2003) by using nonhuman subjects and the results of Rudy et al. (1977) by using exteroceptive (audiovisual and handling) stimuli. All subjects received preexposure and conditioning in a single session. In some groups, the transition between preexposure and conditioning occurred without interruption, whereas in other groups it was marked by the presentation of salient, task-irrelevant stimulation ${ }^{1}$ (analogous to redundant in- 
structions in human preparations). The task-irrelevant stimulation used in the present experiments was either (1) a series of audiovisual stimuli (Experiments 1A, 2, and 3) or (2) handling (Experiment 1B). We hypothesized that interpolating task-irrelevant stimulation between preexposure and conditioning would effectively segregate the local context of preexposure from the local context of conditioning and have the same effect that irrelevant stimulation (i.e., redundant instructions) had in the human preparation of Escobar et al. Thus, latent inhibition should be maximal in the groups in which preexposure and conditioning occurred without interruption.

\section{EXPERIMENTS 1A AND 1B}

Experiments 1A and 1B were direct tests of our hypothesis that interpolation of salient, irrelevant stimulation between preexposure and conditioning would disrupt latent inhibition in a nonhuman (rat) preparation, much in the same way that redundant instructions do in human preparations. In Experiments 1A and 1B, three groups of rats received preexposure and conditioning in a single training session. The subjects in Groups Latent Inhibition (LI) and Break received preexposure and conditioning with target CS X, and subjects in Group Control received preexposure with control CS A and conditioning with target CS X (see Table 1). Thus, the effects of CS preexposure, if any, should be observed in Groups LI and Break, which received preexposure to the target $\mathrm{CS}, \mathrm{X}$, but not in Group Control, which did not receive preexposure to CS X. In Groups LI and Control, the transition between preexposure and conditioning occurred without interruption, whereas task-irrelevant stimulation was presented to Group Break between preexposure and conditioning (i.e., there was a "break" in the continuity between preexposure and conditioning). If interpolation of irrelevant stimulation between preexposure and conditioning disrupts latent inhibition, retardation of behavioral control to CS X (i.e., latent inhibition) should be greater in Group LI than in

Table 1

Design of Experiments 1A and 1B

\begin{tabular}{lcccc}
\hline Group & Preexposure & Transition & Conditioning & Test \\
\hline Control & $36 \mathrm{~A} / 36 \mathrm{Y}$ & context only & $3 \mathrm{X}-\mathrm{US}$ & $\mathrm{X}$ ? Y? \\
LI & $36 \mathrm{X} / 36 \mathrm{Y}$ & $\begin{array}{l}\text { context only } \\
\text { task-irrelevant } \\
\text { Break }\end{array}$ & $36 \mathrm{X} / 36 \mathrm{X}$-US & X? Y \\
& & $\begin{array}{c}\text { stimuli } \\
\text { X }\end{array}$ & $\mathrm{X}$ ? \\
\hline
\end{tabular}

Note-CSs A, X, and Y were a click train, a high-frequency complex tone, and a low-frequency complex tone, counterbalanced within groups. The US was a $0.8-\mathrm{mA}$ footshock delivered for $0.5 \mathrm{sec}$. Intermixed trials are separated by a slash. In Experiment $1 \mathrm{~A}$, the task-irrelevant stimuli were 15 -sec cycles of a 5 -sec flashing light, $5 \mathrm{sec}$ of a buzzing sound, and $5 \mathrm{sec}$ of no stimulus presented in pseudorandom order 18 times (total duration of the transition phase $=4.5 \mathrm{~min}$ ). In Experiment 3, the taskirrelevant stimuli were $4.5 \mathrm{~min}$ of handling. The preexposure, transition, and conditioning phases occurred on a single day of treatment. Testing for responding to CSs X and Y occurred in 2 separate days, with test order counterbalanced within groups. The number in front of the trial type denotes the number of those trials presented in each phase.
Group Break. Exposing Groups Break and LI to a similar interval between preexposure and conditioning ensured that any attenuation of latent inhibition observed in Group Break was not the result of such a retention interval, which (when much longer) has been shown to attenuate latent inhibition in some preparations (e.g., Aguado, Symonds, \& Hall, 1994, Experiment 3).

In Experiment 1A, the task-irrelevant stimulation was a pseudorandom sequence of salient audiovisual stimuli. We controlled for potential nonassociative increases in responding to all stimuli independent of their training history due to the presentation of the interpolated stimulation (i.e., sensitization) by preexposing all subjects to CS Y, which was not paired with the US and was tested in a manner equivalent to CS X. Nonassociative increases in responding due to the interpolated stimulation should be evident as differences in responding to CS Y between Group Break and Groups LI and Control. Experiment 1B assessed the generality of the Experiment $1 \mathrm{~A}$ manipulation: The same design was used, but the irrelevant stimulation presented between preexposure and conditioning consisted of a handling manipulation instead of audiovisual stimuli. Importantly, in Experiment 1B, the animals were not handled from the moment in which they were single-housed for the experiment (5 days prior to Day 1) until the first day of experimental treatment (up to that point, they had been housed in pairs and handled three times per week for $30 \mathrm{sec}$ ). Moreover, the animals were not exposed to the experimental context until their first training day; therefore, placement into and removal from the experimental context was a highly salient event for the animals. Notably, latent inhibition treatment is usually given in multiple sessions, with the animals therefore being handled frequently between sessions. Such frequent handling might result in the handling manipulation becoming part of the treatment context (see the Discussion).

Method
Subjects
The subjects were 18 male (278-388 g [Experiment 1A] and
295-365 g [Experiment 1B]) and 18 female (188-278 g [Exper-
iment 1A] and 189-239 g [Experiment 1B]) Sprague-Dawley,
naive, young adult rats, bred in our colony. All subjects were housed
in pairs and handled for 30 sec three times per week from wean-
ing until 1 week prior to the initiation of the study. At this point,
the subjects were individually housed in wire mesh hanging cages
and maintained on a 16:8-h light:dark cycle. Water availability was
progressively reduced to 30 min per day, provided approximately
2 h after any scheduled treatment. The subjects had free access to
food in the home cage. Subjects in Experiment $1 \mathrm{~A}$ continued to be
handled for 30 sec three times per week from the moment they were
individually housed until the initiation of the study, whereas those in
Experiment 1B were not handled from the moment they were indi-
vidually housed until the first day of experimental manipulation.

\section{Apparatus}

The apparatus consisted of 12 chambers, each measuring $30 \times$ $30 \times 27 \mathrm{~cm}(1 \times \mathrm{w} \times \mathrm{h})$. The side walls of the chamber were made of stainless steel sheet metal, and the front wall, back wall, and ceiling of the chamber were made of clear Plexiglas. The floor was 
constructed of $0.3 \mathrm{~cm}$ diameter rods, spaced $1.3 \mathrm{~cm}$ center to center and connected by NE- 2 neon bulbs that allowed a constant-current footshock to be delivered by means of a high voltage AC circuit in series with a $1.0-\mathrm{M} \Omega$ resistor. Each chamber was housed in an environmental isolation chest that was dimly illuminated by a houselight (1.12 W, No. 1820 incandescent bulb) mounted on the left wall of the experimental chamber. All chambers were equipped with a water-filled lick tube (opening $=0.3 \mathrm{~cm}$ in diameter) that extended about $1 \mathrm{~cm}$ from the rear of a niche $(4 \times 4 \times 5.5 \mathrm{~cm})$ placed on the left side of the front wall. The lick tube entered the center of this niche at $3.3 \mathrm{~cm}$ above the niche floor, which was at the level of the grid floor. An infrared photo beam was projected horizontally across the niche, $1 \mathrm{~cm}$ in front of the lick tube. In order to drink from the tube, subjects had to insert their heads into the niche, thereby breaking the horizontal infrared photo beam. Thus, the amount of time the photo beam was disrupted could be monitored; this served as our dependent variable.

Ventilation fans in each enclosure provided a constant 76-dB (C) background noise. Three $45-\Omega$ speakers mounted on the interior walls of each environmental chest were used to deliver a highfrequency complex tone $(3,000$ and $3,200 \mathrm{~Hz}$, presented simultaneously), a low-frequency complex tone $(80$ and $100 \mathrm{~Hz}$, presented simultaneously), and a click train $(6 / \mathrm{sec})$. A speaker mounted on the exterior side of the animal enclosure was used to deliver a buzzing sound. All auditory cues were $8 \mathrm{~dB}(\mathrm{C})$ above the background. A $150-\mathrm{W}$ bulb (nominal at $120 \mathrm{~V} \mathrm{AC}$, driven at $85 \mathrm{~V} \mathrm{AC}$ ) mounted on the interior back wall of the environmental chest could deliver a flashing $(0.5 \mathrm{sec}$ on $/ 0.5 \mathrm{sec}$ off $)$ light.

\section{Procedure: Experiment 1A}

Acclimation. On Day 1, all subjects were acclimated to the experimental context for 60 min with lick tubes present. No stimuli were presented during this session.

Treatment. On Day 2, all subjects received the experimental treatment scheduled for their condition in the absence of the lick tube. During the preexposure phase, subjects received 36 exposures to either CS X (Groups LI and Break) or CS A (Group Control). All subjects also received 36 exposures to CS Y. CSs A, X, and Y were the click train, high-frequency tone, and low-frequency tone, counterbalanced within groups; CS presentations were $10 \mathrm{sec}$ in duration. Onset of CSs X (or A) and Y occurred with a mean interval of $2( \pm 1)$ min (onset to onset), in pseudorandom order, with the constraint that no more than three trials of the same type would occur in succession. The first stimulus presentation occurred $2 \mathrm{~min}$ into the session. The total duration of the preexposure phase was $144 \mathrm{~min}$. Two minutes after the last preexposure CS presentation, the transition phase began. The subjects in Group Break received 18 presentations of a 15-sec audiovisual stimulus cycle composed of $5 \mathrm{sec}$ of flashing light, $5 \mathrm{sec}$ of buzzing sound, and $5 \mathrm{sec}$ of silence in pseudorandom order, with the constraint that the last stimulus in a cycle could not be the first stimulus in the subsequent cycle. The subjects in Groups LI and Control were exposed to the training context with no stimulus presentations during an equivalent period of time (i.e., $4.5 \mathrm{~min}$ ). Two minutes after completion of the transition phase (i.e., $8.5 \mathrm{~min}$ after the last preexposure CS presentation), the conditioning phase began. All subjects received three CS X-US pairings, with a $10( \pm 2)$ min CS onset to CS onset interval. The US was a $0.8-\mathrm{mA}$ footshock delivered for $0.5 \mathrm{sec}$ immediately upon termination of CS X. After the last conditioning trial, the subjects remained in the test context for an extra $6.5 \mathrm{~min}$, and then they were returned to their home cages. The total duration of the conditioning phase was $27.5 \mathrm{~min}$. The total duration of the treatment session was $3 \mathrm{~h}$. Because of the length of the session, the animals were observed hourly to ensure that they were awake and alert during the stimulus presentations. These observations were as unintrusive as possible (they were made through a small observation window in the envi- ronmental chest), and suggested that all the animals were awake and active throughout the experimental session.

Reacclimation. On Days 3 and 4, all subjects were reacclimated to the experimental context in a 60 -min session. These sessions were intended to reestablish stable drinking behavior, which might have been disrupted by the footshock US. ${ }^{2}$ The subjects had free access to the lick tubes, and no nominal stimuli were presented. A large number of the subjects exhibited long latencies on Day 3. Thus, all subjects received an extra 60-min exposure to the context with lick tubes present on Day 3 in this and subsequent experiments, approximately $2 \mathrm{~h}$ after their scheduled reacclimation session. (Note that exposure to the context during reacclimation extinguishes to some degree the CS-context associations that, according to some theoretical perspectives, underlie latent inhibition. However, the identical amount of exposure to the context received by all groups should have prevented any differential effects of context exposure on a particular group.)

Testing. On Days 5 and 6, all subjects were tested once each for conditioned lick suppression to CS X and to CS Y, with test order counterbalanced across days within groups. On both tests, the time each subject spent drinking upon placement in the test chamber was recorded. The first measure taken was the time it took the subject to complete 5 cumulative seconds of licking in the absence of any nominal stimulus; this measure constituted our baseline scores. Immediately upon completion of the baseline requirement, the test CS was presented; thus, all subjects were drinking at the time of test $\mathrm{CS}$ onset. The time it took to complete 5 additional cumulative seconds of licking in the presence of the test CS was recorded. The latter scores presumably reflected the subjects' expectancy of the US to follow the test CS. A ceiling score of $15 \mathrm{~min}$ was imposed on the time needed to complete 5 cumulative seconds of drinking in the presence of the test CS. On Day 5, the test CS remained on for $15 \mathrm{~min}$, irrespective of the time taken by the subject to complete the 5 cumulative seconds of licking in the CS's presence; that is, all subjects were exposed to the test CS for the same amount of time. This exposure was intended to minimize any potential differential effect of generalized extinction to the CS to be tested on Day 6. The test sessions were approximately $16 \mathrm{~min}$ in duration.

\section{Procedure: Experiment 1B}

The procedure was identical to that described in Experiment 1A (see Table 1), with the exceptions of (1) the omission of an acclimation session and (2) a change in the nature of the stimulation presented between preexposure and conditioning, which in Experiment 1B consisted of handling rather than an audiovisual stimulation. Two minutes after the last CS-preexposure presentation, the subjects in Group Break were removed from the experimental chambers, taken to their home cages where they stayed for $1 \mathrm{~min}$, and then returned to the experimental context to receive their scheduled conditioning treatment. The total time these subjects spent out of the training chambers was $4.5 \mathrm{~min}$. The first conditioning trial started 2 min after the subjects in Group Break were returned to the experimental apparatus. Thus, there was an 8.5 -min interval between the last CS-preexposure presentation and the first conditioning trial. During this time period, the animals in Groups LI and Control remained in the experimental apparatus without disruption.

In this and all subsequent experiments, all test scores were converted to $\log \mathrm{sec}$ (base 10) in order to better meet the normality assumptions of parametric statistical tests. Following the convention of our laboratory, the data from all animals taking over $60 \mathrm{sec}$ to complete their baseline licking during testing (i.e., prior to onset of the test CS) on either test day were eliminated from the analyses because such long latencies presumably reflect an unusual fear of the context (baseline criterion). As a result of this criterion, the data from 1 subject from each of the three treatment groups (Experiment 1A) and the data from 4 animals in Group Break (Experiment 1B) were ex- 
cluded from the analyses. A two-tailed alpha level of .05 was adopted for all statistical tests.

\section{Results and Discussion}

\section{Preliminary Analyses}

Because the flooding measure used in this study might have resulted in test order effects (i.e., generalization of extinction from the first test to the second test), for each experiment, the effect of test order was assessed using a 3 (group: Break vs. LI vs. Control, between-subjects factor) $\times 2$ (test order: XY vs. YX, between-subjects factor) $\times$ 2 (test stimulus: X vs. Y, within-subjects factor) ANOVA. These tests revealed neither a main effect of test order nor an interaction between test order and the other factors. Thus, all subsequent analyses were performed pooling the data for each CS across test days.

\section{Experiment 1A}

Preexposure to $\mathrm{CS} X$ resulted in attenuated behavioral control by this stimulus (i.e., latent inhibition), but only if preexposure and conditioning occurred without interruption (i.e., Group LI exhibited lower latencies to resume drinking than did Groups Break and Control; see Figure 1). The high latencies during presentation of CS X observed in Group Break appeared to be associative because the latencies to resume drinking during presentation of CS Y were not affected by the stimulation interpolated between preexposure and conditioning. The following analyses support these conclusions.

A one-way ANOVA on the baseline scores recorded during testing with CS X was not significant $[F(2,30)<1$, $\left.M S_{\mathrm{e}}=0.02\right]$, suggesting similar baseline drinking across the treatment groups. A one-way ANOVA conducted on the scores recorded during the test presentation of CS X was significant $\left[F(2,30)=14.87, M S_{\mathrm{e}}=0.20, p<.001\right]$. Planned comparisons revealed that Group LI differed from Group Control $[F(1,30)=23.31, p<.001]$, which reflects the effectiveness of our procedure in yielding latent inhibition. Of greater interest to the present study, Group Break also differed from Group LI $[F(1,30)=$ $21.25, p<.001]$, suggesting that interpolation of irrelevant stimulation between preexposure and conditioning attenuated latent inhibition. Indeed, there were no differences in responding to CS X between Groups Break and Control $(F<1)$. Importantly, the retention interval itself between preexposure and conditioning was not the factor that produced an attenuation of latent inhibition in Group Break; despite the fact that all groups experienced the same interval between preexposure treatment and conditioning, Group LI exhibited robust latent inhibition.

Baseline responding during the CS Y test was similar among the groups $\left[F(2,30)<1, M S_{\mathrm{e}}=0.10\right]$. Most important, the latencies recorded during the CS Y presentation were also similar among the groups $[F(2,30)=2.11$, $\left.M S_{\mathrm{e}}=0.09, p>.10\right]$. Thus, the attenuation in latent inhibition to CS X observed in Group Break was not due to a nonassociative increase in responding to all (trained and untrained) stimuli due to the interpolated stimulation. To support this conclusion, we conducted a 3 (group: Break vs. LI vs. Control, between-subjects factor) $\times 2$ (test stimulus: X vs. Y, within-subjects factor) ANOVA, which revealed main effects of group $\left[F(2,30)=12.89, M S_{\mathrm{e}}=\right.$ $0.18, p<.001]$, and test stimulus $[F(1,30)=57.51$, $\left.M S_{\mathrm{e}}=0.11, p<.001\right]$, and, more important, a group $\times$

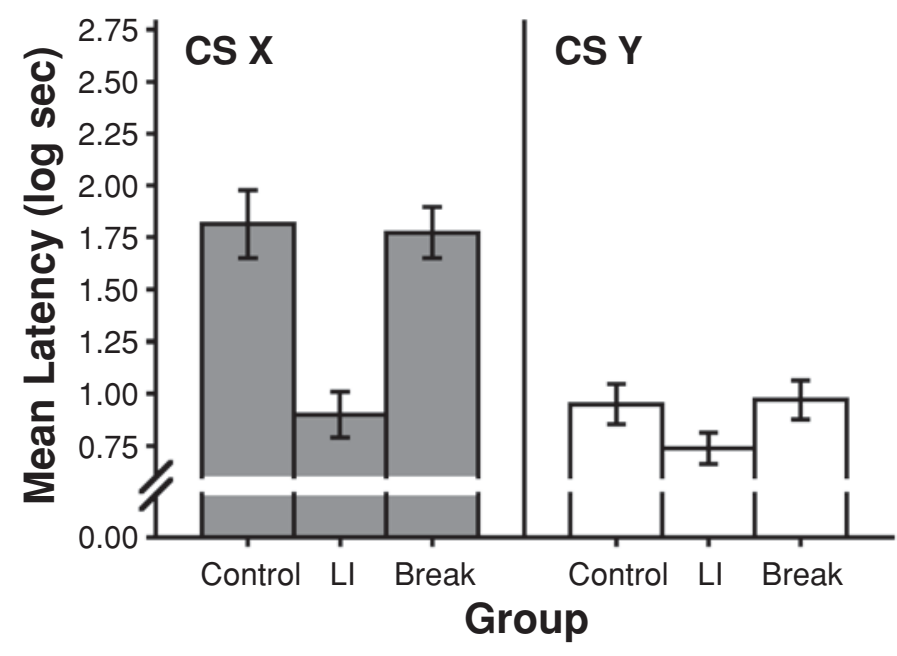

Figure 1. Results of Experiment 1A. The left panel presents responding to CS X, which was subject to latent inhibition treatment in Groups LI and Break; the right panel presents responding to CS Y, which received preexposure equivalent to $C S X$ but was not paired with the US. Latent inhibition is evident in the lower responding to CS X in Group LI than in Group Control. With training equivalent to Group LI, latent inhibition was disrupted in Group Break by the presentation of irrelevant stimulation between preexposure and conditioning (see text for details). Error bars represent the standard errors of the means. 
test stimulus interaction $\left[F(2,30)=7.80, M S_{\mathrm{e}}=0.11\right.$, $p<.005]$.

\section{Experiment 1B}

The handling procedure had the same effect as the presentation of audiovisual stimuli: Latent inhibition was observed in Group LI, relative to Group Control, and it was attenuated in Group Break, relative to Group LI (see Figure 2).

A one-way ANOVA conducted on the baseline scores recorded during testing just prior to the onset of CS X was not significant $\left[F(2,29)=1.39, M S_{\mathrm{e}}=0.04, p=.26\right]$, suggesting similar baseline drinking across treatment groups. A one-way ANOVA conducted on the scores recorded during the test presentation of CS X was significant $\left[F(2,29)=12.40, M S_{\mathrm{e}}=0.14, p<.001\right]$. Planned comparisons revealed that Group LI differed from Group Control $[F(1,29)=22.47, p<.001]$, which is indicative of latent inhibition. Importantly, Group Break also differed from Group LI $[F(1,29)=12.16, p<.005]$, suggesting that handling between the preexposure and conditioning phases attenuated latent inhibition. Consistent with this conclusion, responding to CS X was not different between Groups Break and Control $(F<1)$.

Baseline responding on the CS Y test was analyzed with a one-way ANOVA, which yielded no significant differences among groups $\left[F(2,29)<1, M S_{\mathrm{e}}=0.07\right]$. Similarly, an analysis of the latencies recorded during the test presentation of CS Y was not significant $[F(2,29)=$ $\left.3.27, M S_{\mathrm{e}}=0.09, p>.05\right]$, suggesting that the handling manipulation in Group Break did not indiscriminately increase responding to stimuli that had not been paired with the US. A 3 (group: Break vs. LI vs. Control) $\times 2$ (test stimulus: X vs. Y) ANOVA revealed main effects of group $\left[F(2,29)=14.16, M S_{\mathrm{e}}=0.12, p<.001\right]$, and test stimulus $\left[F(1,29)=46.17, M S_{\mathrm{e}}=0.11, p<.001\right]$, as well as a marginal interaction $\left[F(2,29)=2.77, M S_{\mathrm{e}}=0.11, p=\right.$ .08]. Despite the interaction falling short of significance, the lack of differences among groups in responding to CS Y suggests that there were no differential effects of the handling treatment on behavioral control by CS Y.

\section{Conclusion}

Consistent with the findings in the human preparation of Escobar et al. (2003), interpolation of task-irrelevant stimulation between the preexposure and conditioning phases of a latent inhibition treatment resulted in disrupted latent inhibition. We can infer from Experiments $1 \mathrm{~A}$ and 1B that interpolation of any type of novel, salient stimulation between preexposure and conditioning attenuates latent inhibition. Parsimony leads us to expect that the effects on latent inhibition of different types of stimulation will be similar.

The CS Y data suggest that the interpolated stimulation did not result in nonassociative increases in responding to all stimuli. Indeed, responding to CS Y averaged 0.98 $\log \sec$ (approximately $9.8 \mathrm{sec}$ ), which represents almost no disruption of drinking behavior on the part of the animals to complete the required 5 cumulative seconds of drinking. However, it is possible that presenting salient stimulation at some point during training sensitized the animals to and enhanced learning about the experiences that followed soon after the interpolated stimulation, a potential confound that would not have been detected by our

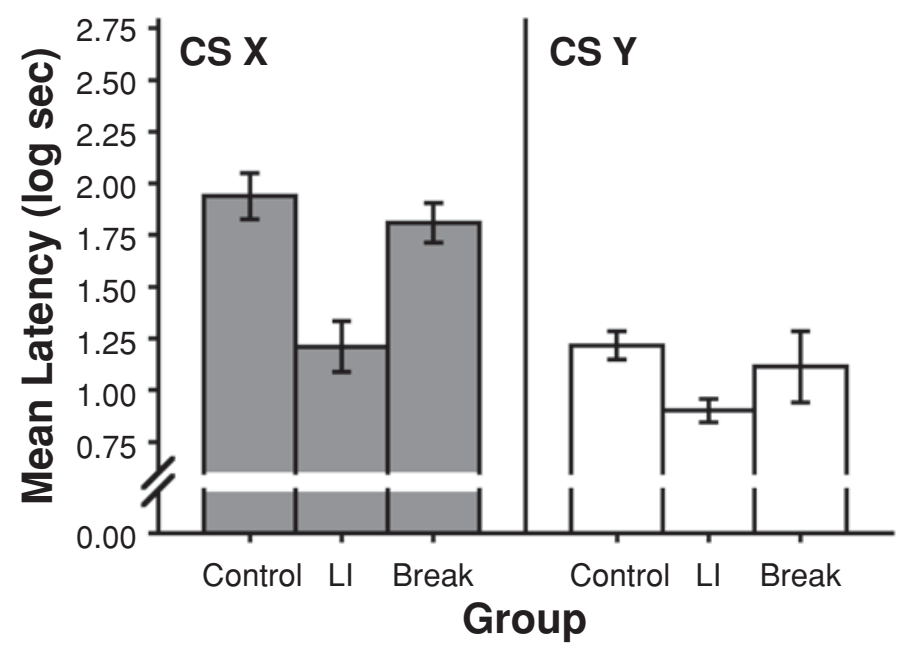

Figure 2. Results of Experiment 1B. The left panel presents responding to CS X, which was subject to latent inhibition treatment in Groups LI and Break; the right panel presents responding to CSY, which received preexposure equivalent to $C S X$ but was not paired with the US. Latent inhibition is evident in the lower responding to CS X in Group LI than in Group Control. With training equivalent to Group LI, latent inhibition was disrupted in Group Break by presenting irrelevant stimulation between preexposure and conditioning (see text for details). Error bars represent the standard errors of the means. 
testing with CS Y. Even though observation of the animals during the audiovisual stimuli presented between preexposure and conditioning suggested that habituation to these stimuli (i.e., a lack of orienting response) occurred within the first of the 4.5 transition minutes, the possibility of enhanced learning about the events that followed soon after these stimuli was addressed in Experiment 2.

\section{EXPERIMENT 2}

Experiments 1A and 1B showed that interpolation of task-irrelevant stimulation does not result in nonassociative increases in responding to stimuli that were preexposed but were not paired with the US during the conditioning phase (i.e., responding to CS X but not CS Y was enhanced in Group Break). A different possibility is that interpolation of salient, task-irrelevant stimulation during the transition phase enhanced learning of the later trained CS-US association because it either sensitized subjects to salient stimulation (in this case, footshock or the CS) or increased the associability of the CS. Experiment 2 was designed to assess this possibility.

Four groups of rats received preexposure and conditioning training in a single session (see Table 2). The preexposed groups (Groups Preexposed-Break and PreexposedContext) received preexposure to the target CS, X, whereas the nonpreexposed groups (Groups NonpreexposedBreak and Nonpreexposed-Context) were preexposed to CS A. After completion of the preexposure treatment, the break groups were presented with task-irrelevant stimulation, whereas the context groups remained in the treatment context with no nominal stimulus presentations (transition phase). Because there were no obvious differences in the pattern of responding obtained from interpolating audiovisual (Experiment 1A) or handling (Experiment 1B) stimulation, audiovisual stimuli were used as the taskirrelevant, interpolated stimulation in Experiments 2 and 3. Immediately following the transition phase, all groups in Experiment 2 received conditioning with CS X (i.e., CS X-US pairings). There were three CS X-US pairings in the preexposed groups and one CS X-US pairing in the nonpreexposed groups. This particular number of conditioning trials was selected to avoid a potential ceiling effect in the nonpreexposed groups. If interpolation of irrel- evant stimulation between preexposure and conditioning increases the effectiveness of the US or the associability of the CS during the subsequent conditioning phase, such an enhancement in conditioning should be observed in both the Preexposed-Break and Nonpreexposed-Break groups.

\begin{abstract}
Method
Subjects and Apparatus

The subjects were 24 male (180-390 g) and 24 female (180 295 g) Sprague-Dawley, naive, young adult rats, bred in our colony and housed and maintained as in Experiment 1A. The apparatus was the same as that described in Experiment 1A.
\end{abstract}

\section{Procedure}

The procedure was identical to that of Experiment 1A, with the exceptions of the preexposure and conditioning treatments, which were adapted to the specific purposes of Experiment 2, and the testing phase, which involved one test with CS X only. During the preexposure phase, all subjects received 36 presentations of either CS X (Groups Preexposed-Break and Preexposed-Context) or CS A (Groups Nonpreexposed-Break and Nonpreexposed-Context), with a mean CS onset-to-CS onset interval of $4( \pm 1.5) \mathrm{min}$. (Note that the average interval between preexposure CS presentations in this experiment was the same as in Experiment 1A. In Experiment 1A, the mean interval between presentations of any CS was $2 \mathrm{~min}$, but the mean interval between presentations of a specific CS (X or $\mathrm{Y}$ ) was $4 \mathrm{~min}$ ). Upon completion of preexposure, the transition phase began. Subjects in Groups Preexposed-Break and NonpreexposedBreak were presented with the task-irrelevant stimulation described in Experiment 1A for 4.5 min; subjects in Groups PreexposedContext and Nonpreexposed-Context remained in the experimental context for an equivalent amount of time (the 8.5 min transition phase). During conditioning, subjects in the preexposed groups received three CS X-US pairings scheduled as in Experiment 1A. Subjects in the nonpreexposed groups received one CS X-US pairing, which occurred simultaneously with the second pairing scheduled for the preexposed groups. CSs X and A were the click and the highfrequency tone, counterbalanced within groups.

Following the baseline criterion described in Experiment 1A, the data from 2 animals from Group Preexposed-Context and 1 animal from Group Nonpreexposed-Context were excluded from the analyses.

\section{Results and Discussion}

Preexposure to CS X resulted in latent inhibition (i.e., Group Preexposed-Context exhibited lower latencies to resume drinking than Group Nonpreexposed-Context),

Table 2

Design of Experiment 2

\begin{tabular}{lclcc}
\hline \multicolumn{1}{c}{ Group } & Preexposure & \multicolumn{1}{c}{ Transition } & Conditioning & Test \\
\hline Preexp-Break & $36 \mathrm{X}$ & task-irrelevant stimuli & $3 \mathrm{X}-\mathrm{US}$ & $\mathrm{X}$ ? \\
Preexp-Cxt & $36 \mathrm{X}$ & context only & $3 \mathrm{X}-\mathrm{US}$ & $\mathrm{X}$ ? \\
Nonpreexp-Break & $36 \mathrm{~A}$ & task-irrelevant stimuli & $1 \mathrm{X}-\mathrm{US}$ & $\mathrm{X}$ ? \\
Nonpreexp-Cxt & $36 \mathrm{~A}$ & context only & $1 \mathrm{X}-\mathrm{US}$ & $\mathrm{X}$ ? \\
\hline
\end{tabular}

Note-CSs A and X were a click train and a high-frequency complex tone, counterbalanced within groups. The US was a $0.8-\mathrm{mA}$ footshock delivered for $0.5 \mathrm{sec}$. The task-irrelevant stimuli were 15 -sec cycles of a 5 -sec flashing light, $5 \mathrm{sec}$ of a buzzing sound, and $5 \mathrm{sec}$ of no stimulus presented in pseudorandom order 18 times (total duration of the transition phase $=4.5 \mathrm{~min}$ ). The preexposure, transition, and conditioning phases occurred in a single day of treatment The number in front of the trial type denotes the number of those trials presented in each phase. 
but only if preexposure and conditioning occurred without interruption (i.e., latent inhibition was not evident in Group Preexposed-Break). Enhanced acquisition attributable to the task-irrelevant audiovisual stimulation interpolated between preexposure and conditioning having increased the effectiveness of the US appears not to adequately explain the attenuation of latent inhibition observed in the preexposed group that received taskirrelevant stimulation during the transition phase (i.e., Groups Nonpreexposed-Break and NonpreexposedContext did not differ from each other). The following analyses support these conclusions.

A one-way ANOVA conducted on the latencies to drink for 5 cumulative seconds recorded prior to the test trial CS presentation (i.e., baseline scores) revealed no differences among groups in baseline licking behavior $[F(3,41)=$ $\left.1.10, M S_{\mathrm{e}}=0.08, p>.35\right]$. That is, there were no differences in fear of the treatment context due to experience with the US during the conditioning phase.

The design of Experiment 2 was a 2 (preexposure treatment: preexposure vs. no preexposure) $\times 2$ (interpolated event: context vs. break stimulus) factorial design. However, the number of conditioning trials was confounded with one of the factors (preexposure treatment): All animals in the preexposed condition received three conditioning trials, whereas all animals in the control condition received one conditioning trial (to avoid a ceiling effect). The difference in the number of trials created several problems because one-trial conditioning preparations are more sensitive to factors outside the scheduled treatment that may influence the effectiveness of the conditioning treatment. In our preparation, which used a footshock US, factors such as humidity and the subject's body weight may have affected the saliency of the shock. Specifically, larger subjects may have experienced a less intense shock than smaller subjects because shock diffuses better through a larger body mass. Additionally, due to the nature of the shock generator, the subjects that experienced their conditioning trial under more humid conditions may have received a slightly less intense shock than subjects that experienced their conditioning trial under drier conditions. Urination as a result of shock increases humidity over shocks given in the same apparatus, and the increased humidity lingers into the treatment of the next animal in that apparatus. Humidity differences are usually minimized by the use of multiple training trials, as humidity rapidly peaks, thus minimizing the differential effects of humidity across animals. In order to control for the potential effect of these factors on the one-trial conditioning groups, running squad (defined as a group of 12 subjects that were placed in the 12 experimental chambers at the same time) was used as a third factor in the analy-

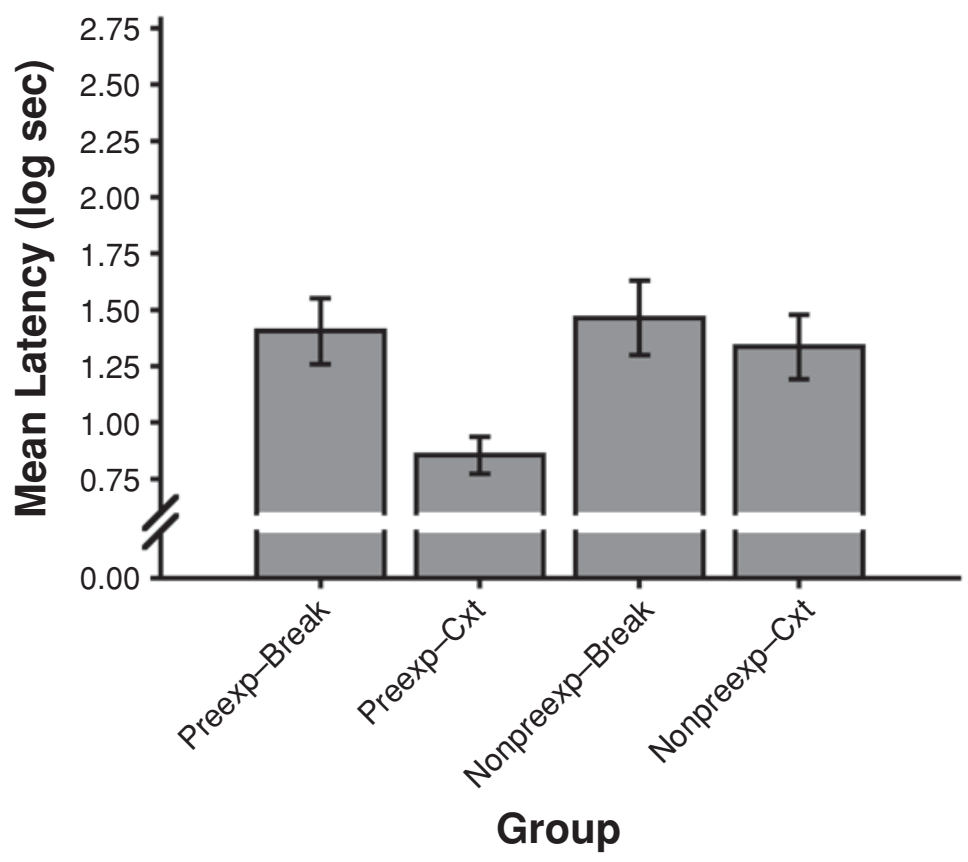

Figure 3. Results of Experiment 2. CS X was subject to latent inhibition treatment in the preexposed but not the nonpreexposed groups. The break groups received task-irrelevant stimulation between preexposure and conditioning, whereas the context groups received equivalent exposure to the treatment context. Latent inhibition is evident in the lower responding to CS X in Group Preexposed-Context than in Group Nonpreexposed-Context. The lack of difference between the two nonpreexposed groups suggests that sensitization is not the only factor underlying the disruption of latent inhibition observed in Group Preexposed-Break (see text for details). Error bars represent the standard errors of the means. 
ses, and all latency scores were adjusted for subject body weight. Figure 3 presents the unweighted means for Experiment 2 . The means adjusted for the body weight covariate were $1.43,0.83,1.51$, and $1.34 \log$ sec for groups Preexp-Break, Preexp-Ctx, Nonpreexp-Break, and Nonpreexp-Ctx, respectively.

A 2 (preexposure treatment) $\times 2$ (interpolated event) $\times$ 4 (running squad) analysis of covariance (ANCOVA), using subject's body weight as the covariate, was used to analyze the latencies to drink for 5 cumulative seconds in the presence of the test CS. This test revealed main effects of running squad $\left[F(3,28)=8.28, M S_{\mathrm{e}}=0.14, p<.001\right]$, preexposure treatment $\left[F(1,28)=6.57, M S_{\mathrm{e}}=0.14, p<\right.$ $.05]$, and interpolated event $\left[F(1,28)=10.67, M S_{\mathrm{e}}=\right.$ $0.14, p<.005]$, as well as a marginal preexposure treatment $\times$ interpolated event interaction $[F(1,28)=3.57$, $\left.M S_{\mathrm{e}}=0.14, p=.07\right]$. The occurrence of latent inhibition was assessed by comparing Groups Preexposed-Context and Nonpreexposed-Context. ${ }^{3}$ This test revealed that latent inhibition occurred $[F(1,28)=9.12, p<.01]$. Presentation of task-irrelevant information attenuated latent inhibition; Group Preexposure-Break exhibited higher latencies than Group Preexposure-Context $[F(1,28)=$ $12.99, p<.005]$. The potential sensitizing effects of the interpolated stimulation were assessed by comparing latencies to resume drinking in the presence of CS X in Groups Nonpreexposed-Break and Nonpreexposed-Context. Neither of these groups received preexposure with CS X, but both received one CS X-US pairing. If the interpolated stimulation affects conditioning by sensitizing subjects to the effects of the US, responding to CS X should be greater in Group Nonpreexposed-Break than in Group Nonpreexposed-Context. This was not the case $[F(1,28)=1.10$, $p>$.30]. Importantly, this lack of difference between the nonpreexposed groups did not reflect a ceiling effect, as no subject in either group reached the ceiling score of $900 \mathrm{sec}(2.95 \log \mathrm{sec})$.

Taken together, Experiments 1A, 1B, and 2 suggest that the interpolation of salient, task-irrelevant stimulation between preexposure and conditioning primarily enhances acquired stimulus control by reducing latent inhibition rather than nonassociatively increasing the ef- fectiveness of the US or the associability of the CS (even though this latter process may also play a role; see the General Discussion). Our hypothesis is that the disruption of latent inhibition observed in Experiments 1A, 1B, and 2 resulted from subjects regarding the preexposure and training phases as separate experiences, much as appears to be the case when the context is changed between preexposure and conditioning. This possibility was explored in Experiment 3.

\section{EXPERIMENT 3}

Rudy et al. (1977) suggested that events (in their case, placement of a subject in a black box) experienced between preexposure and conditioning of a taste aversion disrupt latent inhibition only if those interpolated events are novel. Indeed, if their rat subjects were placed in the black box before preexposure, during preexposure, or during conditioning, the disruptive effects of placement in the black box between preexposure and conditioning were attenuated. However, the results of Escobar et al. (2003) with human participants suggested that novelty is not the only reason why interpolating irrelevant stimulation between preexposure and conditioning attenuates latent inhibition. In the Escobar et al. studies, a set of instructions was interpolated between preexposure and conditioning; these instructions were redundant with the initial instructions given to participants, both in their visual characteristics and in their contents. That is, instructions of that sort were not novel to participants. The hypothesis entertained by Escobar et al. was that interpolation of task-irrelevant stimulation (or redundant instructions) between preexposure and conditioning would result in segmentation of the different phases of treatment, so that subjects might fail to integrate the preexposure and conditioning experiences. Here, we hypothesized that such segmentation might be the result of the formation of different local contexts for the preexposure and conditioning treatment, delimited by the interpolated stimulation.

In Experiment 3, five groups of rats received preexposure and conditioning in a single session and, in all groups, task-irrelevant stimulation (audiovisual stimuli,

Table 3

Design of Experiment 3

\begin{tabular}{lllll}
\hline \multicolumn{1}{c}{ Group } & \multicolumn{1}{c}{ Preexposure } & Transition & \multicolumn{1}{c}{ Conditioning } & Test \\
\hline Control & $36 \mathrm{~A} / 10$ irrel. stimuli & irrel. stimuli & $3 \mathrm{X}-\mathrm{US} / 2$ irrel. stimuli & $\mathrm{X}$ ? \\
LI & $36 \mathrm{X} / 10$ irrel. stimuli & irrel. stimuli & $3 \mathrm{X}-\mathrm{US} / 2$ irrel. stimuli & $\mathrm{X}$ ? \\
Transition only & $36 \mathrm{X}$ & irrel. stimuli & $3 \mathrm{X}-\mathrm{US}$ & $\mathrm{X}$ \\
Preexposure & $36 \mathrm{X} / 10$ irrel. stimuli & irrel. stimuli & $3 \mathrm{X}-\mathrm{US}$ & $\mathrm{X}$ \\
Conditioning & $36 \mathrm{X}$ & irrel. stimuli & $3 \mathrm{X}-\mathrm{US} / 2$ irrel. stimuli & $\mathrm{X}$ ? \\
\hline
\end{tabular}

Note-CSs A and X were a click train and a high-frequency complex tone, counterbalanced within groups. The US was a $0.8-\mathrm{mA}$ footshock delivered for $0.5 \mathrm{sec}$. Intermixed trials are separated by a slash. The task-irrelevant stimuli were 15 -sec cycles of a 5 -sec flashing light, $5 \mathrm{sec}$ of a buzzing sound, and $5 \mathrm{sec}$ of no stimulus presented in pseudorandom order 18 times (total duration of the task-irrelevant stimulation $=4.5 \mathrm{~min}$ ). The preexposure, transition, and conditioning phases occurred in a single day of treatment. The number in front of the trial type denotes the number of those trials presented in each phase. 
see Experiment 1A) was interpolated during the transition between these two phases. The audiovisual stimuli were also presented during preexposure (Group Preexposure), during conditioning (Group Conditioning), both during preexposure and conditioning (Groups LI and Control), or neither during preexposure nor during conditioning (Group Transition Only; see Table 3). If the presentation of audiovisual stimuli between the preexposure and conditioning phases creates separate local contexts for the preexposure and conditioning treatments, presentation of these stimuli both during preexposure and conditioning should attenuate the disruptive effect of presenting such stimulation between the preexposure and conditioning phases (i.e., the local context of all phases of treatment would be similarly characterized by containing audiovisual stimulation). If this was the case, behavioral control by CS X should be retarded in Group LI relative to Group Control despite the latter group's receiving the irrelevant stimuli during the transition phase. Disruption of latent inhibition by the interpolated stimulation would be evidenced as greater responding to CS X in Group Transition Only than in Group LI. The hypothesis that the interpolated stimulation must be novel for latent inhibition to be disrupted was addressed by Groups Preexposure and Conditioning, which received presentations of the audiovisual stimuli during preexposure and conditioning, respectively, thus creating situations analogous to those used by Rudy et al. (1977) in their studies. (Note that we could have manipulated novelty by simply exposing the animals to the interpolated stimulation outside the treatment context. However, this manipulation would only partially attenuate novelty because the treatment context-interpolated stimulation compound would still be novel to the animals.)

\section{Method}

\section{Subjects and Apparatus}

The subjects were 30 male $(268-460 \mathrm{~g})$ and 30 female (188$295 \mathrm{~g}$ ) Sprague-Dawley, naive, young adult rats, bred in our colony and housed and maintained as in Experiment 1A. The apparatus was the same as that described in Experiment 1A.

\section{Procedure}

The procedure was identical to that of Experiment 1A, with the exceptions of the preexposure and conditioning treatments, which were adapted to the specific purposes of Experiment 3. Because Experiments 1A, 1B, and 2 demonstrated that nonassociative responding to a CS that had not been paired with the US did not occur in the present preparation and that disruption of latent inhibition by interpolation of task-irrelevant stimulation was not primarily due to increased effectiveness of the US (or associability of the CS) caused by this stimulation, respectively, controls for these potential effects were omitted from this experiment. During preexposure, all subjects received 36 presentations of CS X (Groups LI, Transition Only, Preexposure, and Conditioning) or CS A (Group Control), with a mean CS onset-to-CS onset interval of $4( \pm 1.5)$ min. In 10 of the longest intertrial intervals, which were $5.5 \mathrm{~min}$ in duration, subjects in Groups Control, LI, and Preexposure received presentations of the 4.5 min task-irrelevant stimulation. In this way, the taskirrelevant stimulation was introduced during the preexposure phase. All groups were exposed to the task-irrelevant stimulation during the transition phase just as in the break condition of Experiments 1A,
1B, and 2. During conditioning, all subjects received three CS XUS pairings scheduled as in Experiment 1A. The subjects in Groups Control, LI, and Conditioning received presentations of the $4.5 \mathrm{~min}$ audiovisual stimulation during each of the two intertrial intervals, thereby introducing the task-irrelevant stimulation during conditioning. CSs X and A were the click and the high-frequency tone, counterbalanced within groups.

Following the baseline elimination criterion described in Experiment 1A, the data from 4 animals from each of Groups Transition Only and Conditioning, 3 subjects from Group Preexposure, and 1 subject from each of Groups LI and Control were excluded from the analyses. The data from 1 animal in Group Control were lost due to an equipment failure.

\section{Results and Discussion}

The results of Experiment 3 suggest that presenting irrelevant stimulation between preexposure and conditioning attenuates latent inhibition not because this event is novel (it was not for Group Preexposure), but because it creates separate local contexts for the preexposure and conditioning experiences. When task-irrelevant stimulation was interpolated between preexposure and conditioning, latent inhibition was observed only if the same stimulation was also presented both during preexposure and during conditioning. In contrast, latent inhibition was disrupted when the task-irrelevant stimulation was presented during the transition phase only, during both the preexposure and transition phases, and during both the transition and conditioning phases (see Figure 4). The following analyses support these conclusions.

A one-way ANOVA conducted on the times recorded prior to the presentation of the test CS was significant $\left[F(4,41)=3.76, M S_{\mathrm{e}}=0.23, p<.05\right]$, suggesting that baseline behavior differed between groups (means: 1.51 $[ \pm 0.08], 1.13[ \pm 0.06], 1.27[ \pm 0.11], 1.44[ \pm 0.09]$, and 1.39 [ \pm 0.07$]$; log sec for the groups as presented in Table 3). To adjust the CS scores for the difference in baseline scores, the latencies recorded during the presentation of CS X were analyzed using a one-way analysis of covariance (ANCOVA), with baseline scores as the covariate. Figure 4 displays the unadjusted means for each group. The means, adjusted for the covariate, were 2.30, 1.35, 2.12, 1.91, and $2.14 \log \mathrm{sec}$ for Groups Control, LI, Transition Only, Preexposure, and Conditioning, respectively. The one-way ANCOVA was significant $[F(4,40)=3.60$, $\left.M S_{\mathrm{e}}=0.32, p<.05\right]$. Planned comparisons revealed that, if the stimuli presented during the transition between preexposure and conditioning were also presented during these two phases, latent inhibition was observed (Group LI vs. Group Control) $[F(1,40)=11.24, p<.005]$. Presentation of the task-irrelevant stimulation only during the transition disrupted latent inhibition, as revealed by the difference between Groups Transition Only and LI $[F(1,40)=8.29, p<.01]$. Moreover, if the task-irrelevant stimuli presented during the transition were also presented during either preexposure or conditioning, but not both, latent inhibition was disrupted, as revealed by the differences between Group LI and Groups Preexposure $[F(1,40)=4.98, p<.05]$, and Conditioning $[F(1,40)=$ 


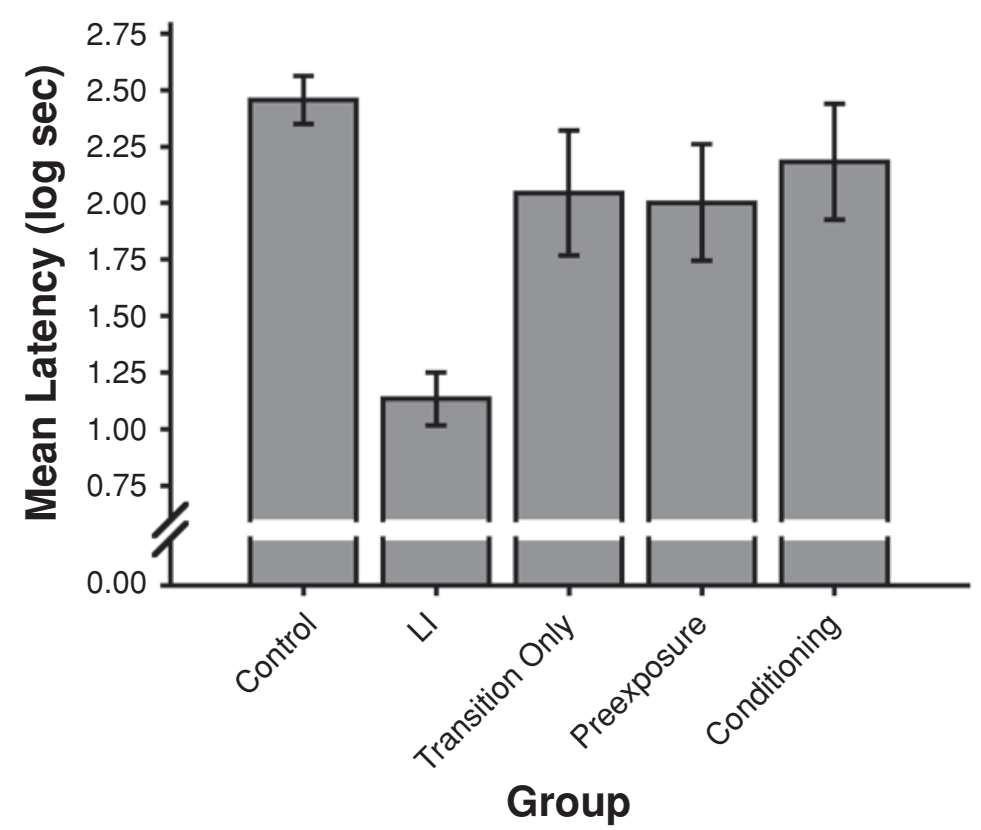

Figure 4. Results of Experiment 3. CS X was subject to latent inhibition treatment in all but the control group. All groups received irrelevant stimulation between preexposure and conditioning. The irrelevant stimulation was also presented during preexposure (Group Preexposure), during conditioning (Group Conditioning), during both preexposure and conditioning (Groups LI and Control), and during neither preexposure nor conditioning (Group Transition Only). Latent inhibition is evident in the lower responding to CS X in Group LI than in Group Control. With equivalent preexposure to CS X, latent inhibition was disrupted by additionally presenting irrelevant stimulation in Group Transition Only, and this attenuation was not affected by additionally presenting the irrelevant stimulation either during preexposure (Group Preexposure) or during conditioning (Group Conditioning; see text for details). Error bars represent the standard errors of the means.

$8.00, p<.01]$. Post hoc tests were conducted to compare responding in Groups Preexposure, Conditioning, Transition Only, and Control. The Scheffé statistic revealed that these groups did not differ from each other (all $p \mathrm{~s}>.55$ ).

A potential concern with the data of Experiment 3 is the relatively large number of subjects eliminated from the analysis because of the baseline criterion. To ensure that eliminating these subjects did not alter the data in a substantial manner, the analyses were repeated, but this time including the data from all subjects (except the one eliminated because of an equipment failure). A oneway ANCOVA performed on the latencies to complete 5 cumulative seconds of licking in the presence of CS X (with baseline scores as the covariate) was significant $\left[F(4,53)=6.77, M S_{\mathrm{e}}=0.31, p<.001\right]$. Group LI differed from Groups Control, Transition Only, Preexposure, and Conditioning $\left[F_{\mathrm{s}}(1,53)=24.70,15.44,10.48\right.$, and 12.21 , respectively; all $p \mathrm{~s}<.005]$. Thus, all response tendencies were unchanged when no data selection criterion was applied.

The present results suggest that interpolation of stimulation between preexposure and conditioning attenuates latent inhibition through a mechanism similar to that of situations in which latent inhibition is attenuated by a physical context change between preexposure and conditioning. Despite the fact that the physical context for preexposure and conditioning were the same in all the experiments reported here, it is possible that presentations of the task-irrelevant stimuli only during preexposure and the transition or only during conditioning and the transition created different local contexts for each of these phases of treatment (one that included the irrelevant stimulation and one that did not include the irrelevant stimulation). Because latent inhibition is highly context-specific (e.g., Channell \& Hall, 1983; Lovibond et al., 1984), such a difference in local contexts might result in attenuated latent inhibition. Notably, the presentation of task-irrelevant stimuli only during the transition between preexposure and conditioning had a similar disrupting effect, suggesting that irrelevant stimulation presented at that particular moment also "segments" the training experiences into separate contexts. This point will be further discussed in the General Discussion. Importantly, and consistent with the results of Experiment 2, the occurrence of latent inhibition in Group LI relative to Group Preexposure suggests that salient, task-irrelevant stimuli presented during CS- 
preexposure phase do not per se attenuate latent inhibition. Rather, the salient stimulation clearly segmented the two phases of treatment, thereby disrupting latent inhibition.

\section{GENERAL DISCUSSION}

Consistent with the results of Escobar et al. (2003) and Rudy et al. (1977), latent inhibition was attenuated when the rats that were preexposed and conditioned with a target CS were presented with task-irrelevant (audiovisual or handling) stimulation between the two phases of the latent inhibition treatment (Experiments 1A, 1B, and 2). We concluded that this stimulation resulted in segmentation of the preexposure and conditioning experiences, potentially creating different local contexts for each phase of treatment. Consistent with this assumption, if the taskirrelevant stimulation was presented not only between preexposure and conditioning but also during both preexposure and conditioning, it had no impact on latent inhibition (Experiment 3). This effect does not seem related to a decrease in novelty of the salient stimulation because if this stimulation was presented during the preexposure and the transition phases, latent inhibition was equally attenuated, despite these presentations having made the stimulation less novel during the transition (Experiment 3 ).

The present experiments were modeled after those of Escobar et al. (2003), who, in a human preparation, observed that latent inhibition was disrupted when redundant instructions were interpolated between preexposure and conditioning, but who observed latent inhibition if preexposure and conditioning occurred without interruption. Escobar et al. suggested that this property of latent inhibition - namely, its disruption by the presentation of task-irrelevant stimulation between preexposure and conditioning - could explain the usual difficulty in observing this effect in adult human participants without the use of a masking task. They hypothesized that the presentation of irrelevant stimulation between preexposure (without a masking task) and conditioning could segment the treatment experiences into two separate contexts, one for preexposure and one for conditioning. Because latent inhibition is highly context-dependent (e.g., Channell \& Hall, 1983; Lovibond et al., 1984), such a segmentation of the treatment context could result in its disruption. The present results suggest that latent inhibition in human and nonhuman subjects follows similar rules, which is indicative of a similar underlying process. This conclusion is of theoretical relevance because there have been some suggestions that the so-called latent inhibition effect in humans, which has been thought to require masked preexposure to the CS, reflects a process other than that which underlies the latent inhibition effect in animals - namely, negative priming 4 (cf. Tipper, 2001; also see Graham \& McLaren, 1998). Escobar et al.'s report of unmasked latent inhibition in a situation in which preexposure and conditioning occur without interruption, in conjunction with the present results in which latent inhibition was attenuated by disrupting the otherwise smooth transition between pre- exposure and conditioning, provides a link between the human and nonhuman latent inhibition research, suggesting that the two literatures can be integrated into a common framework. (However, neither these results nor those of Escobar et al. explain why masking the preexposure experience results in latent inhibition that is less likely to be disrupted by the presentation of task-irrelevant stimulation between preexposure and conditioning. See Escobar et al. for a further discussion of this issue.)

Our results, as well as those of Escobar et al. (2003), are similar to previous reports of latent inhibition disrupted by the introduction of task-irrelevant stimulation between preexposure and conditioning. For example, Rudy et al. (1977) observed that placement of the subjects in a black box between preexposure to a flavor and conditioning of a lithium chloride-induced aversion to that flavor attenuated latent inhibition of the flavor. Rudy et al. suggested that this attenuation of latent inhibition could be related to the novelty of the black box. Indeed, they observed that exposure to the black box before flavor preexposure, during flavor preexposure, or during the experience of lithium chloride-induced illness, reduced the effects of exposure to the black box between preexposure and conditioning.

Rudy et al.'s (1977) observation that the disruptive effects of task-irrelevant stimulation interpolated between preexposure and conditioning could be attenuated by presenting such irrelevant stimulation during preexposure or during conditioning might appear inconsistent with some of our results. In our Experiment 3, exposure to the irrelevant stimulation (pseudorandom presentations of audiovisual stimuli) during preexposure or conditioning was not sufficient to reduce its attenuating effects on latent inhibition, but there are many differences between our procedure and that of Rudy et al. (1977) that could explain these disparate results. First, in the Rudy et al. studies, experience with an external event (a black box) disrupted latent inhibition in a preparation that used an interoceptive US (i.e., internal malaise) for conditioning, whereas in our Experiment 2 the CS, US, and interpolated stimulation were all exteroceptive stimuli. Indeed, Rudy et al. suggested that in their conditioned taste-aversion preparation, placement of the subjects in the black box immediately prior to conditioning attenuated latent inhibition because such exteroceptive stimulation altered the subjects' perception of the interoceptive stimulus (i.e., a taste) during conditioning. However, this difference as a source of the discrepancy is not appealing because the division between interoceptive and external stimulation is not at all clear. Potentially, conditioning in a tone-shock situation is not between the external stimuli defined as tone and shock, but between the internal effects that such stimuli have on the subject; that is, all conditioning could be viewed as involving internal states. A second possible way to reconcile the present results with those of Rudy et al. is in terms of the effect that a context shift between preexposure and conditioning has on latent inhibition. As mentioned previously, latent inhibition is highly context dependent (e.g., Channell \& Hall, 1983; Lovibond et al., 1984). However, there are reports that exposure to a sec- 
ond context prior to CS-preexposure treatment attenuates the context specificity of latent inhibition. McLaren, Bennett, Plaisted, Aitken, and Mackintosh (1994) preexposed water-deprived rats to an auditory CS in Context A. Some rats then received conditioning with the auditory $\mathrm{CS}$ and a water US in Context A, whereas the remaining animals received CS-US pairings in Context $\mathrm{B}$. Rats preexposed and conditioned in Context A exhibited the typical latent inhibition deficit, whereas rats preexposed in Context $\mathrm{A}$ and conditioned in Context $\mathrm{B}$ exhibited disrupted latent inhibition, evidencing the context specificity of latent inhibition. Two further groups of rats were exposed to Context $\mathrm{B}$ prior to preexposure to the auditory $\mathrm{CS}$ in Context $\mathrm{A}$ and then received conditioning in either Context A or Context B. In this case, the change of context between preexposure and conditioning had little attenuating effect on latent inhibition; that is, the pretreatment exposure to Context B resulted in latent inhibition treatment in Context A generalizing to Context B. A similar principle could be applied to the Rudy et al. studies. If we were to regard the black box as a second context, exposure to this box before preexposure, during preexposure, or during conditioning could have resulted in latent inhibition generalizing to other contexts. If placement in the black box between preexposure and conditioning had the effect of segmenting the two treatments (i.e., preexposure and conditioning) into two separate [global] contexts, it is possible that repeated placements in the black box had the effect of making latent inhibition generalize across the contexts created by such exteroceptive stimulation. ${ }^{5}$ In contrast, in our Experiment 3, the animals were not exposed to different global contexts during preexposure and conditioning, but rather received stimuli that might have created separate local contexts (e.g., Barnet et al., 1993, in which local context refers to features that differentiate temporally proximal from temporally distal background stimuli). Thus, because the animals were not exposed to a different global context between preexposure and conditioning, latent inhibition did not generalize across these different local contexts; this is analogous to situations in which changes in global context mask changes in local context.

Experiments 1A, 1B, and 2 were designed to test for two potential alternative explanations of the disrupted latent inhibition that we observed when preexposure and conditioning were separated by task-irrelevant stimulation. Experiments $1 \mathrm{~A}$ and $1 \mathrm{~B}$ showed that responding to an untrained stimulus was not increased by the presentation of irrelevant stimulation (i.e., the increased responding observed in the break condition was associative). Experiment 2 showed that the interpolated stimulation increased neither the effectiveness of the US nor the associability of the CS in such a way that the conditioning resulted in abnormally high levels of responding. We must recognize, however, that both of these factors may play some role in the increased conditioned responding observed in the break condition. Despite the lack of differences among groups responding to $\mathrm{Y}$ in Experiments 1A and $1 \mathrm{~B}$, the pattern of responding to $\mathrm{Y}$ resembled that of
X. Post hoc power analyses (GPOWER; Faul \& Erdfelder, 1992) revealed that the power of the present preparation (i.e., the probability of observing statistically significant differences among groups in responding to $\mathrm{Y}$ ) was 0.13 for Experiment 1A and 0.28 for Experiment 1B. Furthermore, a sample of 117 subjects would be required to observe statistical significance in the test with the highest power (Experiment 1B).

Although Experiment 3 demonstrated that the novelty of the interpolated event is not the only factor influencing the disruption of latent inhibition, novelty does appear to play an important role (Rudy et al., 1977). As previously mentioned, all animals were experimentally naive at the beginning of Experiments 1 A, 2, and 3; that is, they had never been exposed to the audiovisual stimuli that were presented during the transition phase. Moreover, in Experiment $1 \mathrm{~B}$, in which the interpolated stimulation consisted of handling and placement in the home cage, the animals were not handled from the moment they were singly housed until the beginning of the experiment, had never been placed in the transport cart before the treatment day, and had not been returned to their home cages from the experimental apparatus until termination of the preexposure phase. To increase the salience (perhaps equivalent to novelty in this context) of the handling manipulation, we omitted our usual acclimation phase in this study; the first exposure of the animals to experimental handling and the experimental apparatus was during the preexposure phase. This peculiarity in our procedure makes Experiment $1 \mathrm{~B}$ different from experiments in which preexposure and conditioning are given in separate daily sessions after the animals have had experience with the handling cues either because there are multiple sessions of preexposure and/ or conditioning, or because the animals have received an acclimation-to-the-context session.

The present experiments do not allow us to completely dissociate the effects of novelty of the irrelevant stimulation from the effects of salience of this stimulation. We can conclude only that interpolation of a salient, relatively novel event between preexposure and conditioning attenuates latent inhibition. We can hypothesize several mechanisms accounting for this attenuation of latent inhibition. For example, the irrelevant stimulation could have served as a "marking" stimulus (see, e.g., Lieberman, McIntosh, \& Thomas, 1979; Thomas, Robertson, \& Lieberman, 1987), which has traditionally been viewed as a taskirrelevant stimulus that makes the training experiences more memorable. However, marking procedures usually enhance memory of the events immediately preceding presentation of the marking stimulus, whereas in our preparation, the task-irrelevant stimulation increased performance based on the events that immediately followed it. Furthermore, when the task-irrelevant stimulation was presented only during preexposure (Group Preexposure of Experiment 3), latent inhibition was disrupted. That is, the task-irrelevant stimulation did not enhance memory for the events occurring immediately before it (i.e., the preexposure trials), but rather, facilitated retrieval of other events (i.e., the conditioning trials). 
We favor here an explanation of the disruption effects observed in the present experiments that takes into account the perception of the learning experience as occurring in a unitary context. According to this view, interpolation of task-irrelevant stimulation between preexposure and conditioning creates separate contexts for the preexposure and conditioning experiences. Importantly, in the framework of contemporary associative learning theories, there is no apparent reason why this should be the case. Whether one considers latent inhibition to be the result of attenuated attention to (or associability of) the CS due to preexposure (e.g., Lubow, 1989; Lubow, Schnur, \& Rifkin, 1976; Mackintosh, 1975; Pearce \& Hall, 1980), the result of the formation of strong CS-context associations during preexposure (e.g., Miller \& Matzel, 1988; Wagner, 1981), a hybrid between these two mechanisms (e.g., McLaren \& Mackintosh, 2000), or a result of there being different occasion setters for the CS-noUS and CS-US experiences (e.g., Lubow \& Gewirtz, 1995), the stimulation we interpolated between preexposure and conditioning was irrelevant to the mechanisms that have been proposed as underlying causes of latent inhibition. For example, if the observed attenuation of latent inhibition was due to our manipulation's increasing the associability of the CS, we should have observed enhanced responding in Group Nonpreexposed-Break of Experiment 2. However, even if ceiling effects were prevented by our using only one conditioning trial, the level of behavioral control acquired in this group was not different from Group NonpreexposedContext, in which no interpolated stimulation was provided. Similarly, although our results appear most consistent with CS-context association or occasion-setting theories, these theories require that the physical contextual stimuli change between preexposure and conditioning for latent inhibition be disrupted. They incorporate no mechanism to account for an event presented in the transition between the two treatment phases resulting in a change of context. We conclude that the present experiments suggest that learning theories should more closely attend to the impact of variables normally regarded as irrelevant to learning because they can, in certain situations, create different local contexts and, thus, differentiate the training experiences.

\section{REFERENCES}

Barnet, R. C., Grahame, N. J., \& Miller, R. R. (1993). Local time horizons in Pavlovian learning. Journal of Experimental Psychology: Animal Behavior Processes, 19, 215-230.

Bouton, M. E. (1993). Context, time, and memory in the interference paradigms of Pavlovian learning. Psychological Bulletin, 114, 8099.

Braunstein-Bercovitz, H., \& Lubow, R. E. (1998a). Are highschizotypal normal participants distractible or limited in attentional resources? A study of latent inhibition as function of masking task load and schizotypy level. Journal of Abnormal Psychology, 107, 659-670.

Braunstein-Bercovitz, H., \& Lubow, R. E. (1998b). Latent inhibition as a function of modulation of attention to the preexposed irrelevant stimulus. Learning \& Motivation, 29, 261-279.

Channell, S., \& Hall, G. (1983). Contextual effects in latent inhibi- tion with an appetitive conditioning procedure. Animal Learning \& Behavior, 11, 67-74.

DE LA CASA, L. G., \& Lubow, R. E. (2001). Latent inhibition with a response time measure from a within-subject design: Effects of number of preexposures, masking task, context change, and delay. Neuropsychology, 15, 244-253.

Escobar, M., Arcediano, F., \& Miller, R. R. (2003). Latent inhibition in human adults without masking. Journal of Experimental Psychology: Learning, Memory, \& Cognition, 29, 1028-1040.

FAUL, F., \& ERDFELDER, E. (1992). GPOWER: A priori, post-hoc, and compromise power analyses for MS-DOS [Computer program]. Bonn: Bonn University, Department of Psychology.

Ginton, A., UrCa, G., \& Lubow, R. E. (1975). The effects of preexposure to a nonattended stimulus on subsequent learning: Latent inhibition in adults. Bulletin of the Psychonomic Society, 5, 5-8.

Graham, S., \& McLaren, I. P. L. (1998). Retardation in human discrimination learning as a consequence of pre-exposure: Latent inhibition or negative priming? Quarterly Journal of Experimental Psychology, 51B, 155-172.

HaLL, G. (1991). Perceptual and associative learning. Oxford: Oxford University Press.

Hulstisn, W. (1978). The orienting reaction during human eyelid conditioning following preconditioning exposures to the CS. Psychological Research, 40, 77-88.

Kraemer, P. J., Randall, C. K., \& Carbary, T. J. (1991). Release from latent inhibition with delayed testing. Animal Learning \& Behavior, 19, 139-145.

LANTZ, A. E. (1973). Effect of number of trials, interstimulus interval, and dishabituation during CS habituation on subsequent conditioning in a CER paradigm. Animal Learning \& Behavior, 1, 273-277.

Lieberman, D. A., McIntosh, D. C., \& Thomas, G. V. (1979). Learning when reward is delayed: A marking hypothesis. Journal of Experimental Psychology: Animal Behavior Processes, 5, 224-242.

Lovibond, P. F., Preston, G. C., \& Mackintosh, N. J. (1984). Context specificity of conditioning, extinction, and latent inhibition. Journal of Experimental Psychology: Animal Behavior Processes, 10, 360375.

LuBow, R. E. (1973). Latent inhibition. Psychological Bulletin, 79, 398 407.

Lubow, R. E. (1989). Latent inhibition and conditioned attention theory. Cambridge: Cambridge University Press.

Lubow, R. E., \& GewIRTZ, J. C. (1995). Latent inhibition in humans: Data, theory, and implications for schizophrenia. Psychological Bulletin, 117, 87-103.

Lubow, R. E., \& Moore, A. U. (1959). Latent inhibition: The effect of nonreinforced preexposure to the conditioned stimulus. Journal of Comparative \& Physiological Psychology, 52, 415-419.

Lubow, R. E., Schnur, P., \& Rifkin, B. (1976). Latent inhibition and conditioned attention theory. Journal of Experimental Psychology: Animal Behavior Processes, 2, 163-174.

Lubow, R. E., Weiner, I., \& Schnur, P. (1981). Conditioned attention theory. In G. H. Bower (Ed.), The psychology of learning and motivation (Vol. 15, pp. 1-49). New York: Academic Press.

Mackintosh, N. J. (1975). A theory of attention: Variations in the associability of stimuli with reinforcement. Psychological Review, 82, 276-298.

McLaren, I. P. L., Bennett, C., Plaisted, K., Aitken, M., \& MackINTOSH, N. J. (1994). Latent inhibition, context specificity, and context familiarity. Quarterly Journal of Experimental Psychology, 47B, 387-400.

McLaren, I. P. L., \& Mackintosh, N. J. (2000). An elemental model of associative learning: I. Latent inhibition and perceptual learning. Animal Learning \& Behavior, 28, 211-246.

Miller, R. R., \& MATZEL, L. D. (1988). The comparator hypothesis: A response rule for the expression of associations. In G. H. Bower (Ed.), The psychology of learning and motivation (Vol. 22, pp. 51-92). San Diego: Academic Press.

Pearce, J. M., \& Hall, G. (1980). A model for Pavlovian learning: Variations in the effectiveness of conditioned but not of unconditioned stimuli. Psychological Review, 87, 532-552.

Rudy, J. W., Rosenberg, L., \& SAndell, J. H. (1977). Disruption of a 
taste familiarity effect by novel exteroceptive stimulation. Journal of Experimental Psychology: Animal Behavior Processes, 3, 26-36.

SchneIDer, W., \& Shiffrin, R. M. (1977). Controlled and automatic human information processing: I. Detection, search, and attention. Psychological Review, 84, 1-66.

Shiffrin, R. M., \& SchneIDER, W. (1977). Controlled and automatic attentional processing: II. Perceptual learning, automatic attending, and a general theory. Psychological Review, 84, 127-190.

Thomas, G. V., Robertson, D., \& Lieberman, D. A. (1987). Marking effects in Pavlovian trace conditioning. Journal of Experimental Psychology: Animal Behavior Processes, 13, 126-135.

TIPPER, S. P. (1985). The negative priming effect: Inhibitory priming by ignored objects. Quarterly Journal of Experimental Psychology, 37A, 571-590.

TIPPER, S. P. (2001). Does negative priming reflect inhibitory mechanisms? A review and integration of conflicting views. Quarterly Journal of Experimental Psychology, 54A, 321-343.

WAGNER, A. R. (1981). SOP: A model of automatic memory processing in animal behavior. In N. E. Spear \& R. R. Miller (Eds.), Information processing in animals: Memory mechanisms (pp. 5-47). Hillsdale, NJ: Erlbaum.

\section{NOTES}

1. We recognize that all stimulations have the potential to alter behavior, whether or not they are considered relevant by the experimenter. However, we expected robust stimulus control by the training CSs; therefore, we labeled the interpolated stimulation as task-irrelevant.

2 . The necessary introduction of the reacclimation sessions resulted in the test trials occurring at least $48 \mathrm{~h}$ after the last conditioning trial had occurred. This might appear rather unusual, considering that the intertrial intervals during treatment ranged between 2 and $10 \mathrm{~min}$. The imposition of a retention interval between treatment and testing is known to have an attenuating effect on latent inhibition (e.g., Kraemer, Randall, \& Carbary, 1991). Although the retention interval may play a role in the observed attenuation of latent inhibition in Group Break, it should have had a similar attenuating effect in Group LI.

3. Note that these two groups differ with respect to the number of CS X-US pairings they received during the conditioning phase. This difference, however, should work against our observing latent inhibition in this preparation, as it would decrease responding in Group Nonpreexposed-Context.

4. Negative priming refers to the commonly observed attenuated responding to previously ignored stimuli (in most human preparations, the so-called distractors). This operational definition of negative priming supports the commonplace view of latent inhibition, which is that it reflects a change in attention to the CS. However, the phenomenon of negative priming is widely believed to reflect active inhibition of the internal representations of the ignored stimuli, which spreads (i.e., generalizes) to similar stimuli, even if similarity is provided only by their belonging to the same abstract category (see Tipper, 1985, 2001). In contrast, latent inhibition is assumed to be highly stimulus specific and should exhibit little generalization to (conceptually or perceptually) similar stimuli (e.g., Lubow, 1973; for an experimental test, see Graham \& McLaren, 1998).

5. Global contexts can be defined as all events that are present in a particular situation for an extended period of time. Most environmental cues provided by the training chamber would become part of the global context. The concept of global context can be contrasted with the concept of a local context, which would be composed of stimuli that are presented clustered in space and time. Local contexts are usually subsumed by a more general global context.

(Manuscript received August 16, 2004; revision accepted for publication December 13, 2004.) 